\title{
Coupled chemistry-climate model simulations for the period 1980 to 2020: Ozone depletion and the start of ozone recovery
}

\author{
By JOHN AUSTIN* and NEAL BUTCHART \\ Met Office, Bracknell, UK
}

(Received 23 October 2002; revised 6 June 2003)

\section{SUMMARY}

Two simulations of a coupled chemistry-climate model are completed for the period 1980 to 2020, covering the recent past during which extensive satellite ozone and temperature data exist, and covering the near future when ozone levels are expected to begin to recover. In the first simulation, Rayleigh friction is used to decelerate the polar night jet. In the second simulation, a parametrized spectral gravity-wave forcing scheme is included. This has the effect of considerably reducing the model temperature bias in the polar regions and weakening the polar night jet. In the simulations the concentrations of chlorine, bromine and the well-mixed greenhouse gas concentrations are specified in accordance with past observations and future projected values. The calculated trends in temperature and ozone in the two runs are similar, indicating that model internal variability does not have a significant impact and suggesting that the trends arise largely from changes in external parameters. Typically, after about the year 2000, the trend in the modelled annually averaged ozone changed from a decrease to a small increase. The change was found to be statistically significant in the upper stratosphere and in the lower stratosphere over Antarctica, which are the regions most affected by halogen chemistry. Globally averaged temperature results suggest that the best place to look for future atmospheric change is in the upper stratosphere. Decadally averaged statistics are used to estimate the timing of the start of recovery of total ozone. The simulations indicate no significant further ozone loss from the current atmosphere with minima typically occurring in the years from 2000 to 2005, except in the spring Arctic where ozone values continued to decrease slowly until the end of the integrations. One major problem with the detection of the start of ozone recovery, is that the concentrations of halogens are expected to reduce only slowly from their peak value. Hence, no substantial recovery is simulated before the year 2020. The difficulty in detecting the start of ozone recovery suggests the need to continue the model simulations until the second half of this century which would also help to establish the timing of complete ozone recovery.

KEYWORDS: Chlorine Greenhouse gases Stratosphere Trends

\section{INTRODUCTION}

Ozone depletion over the period 1980 to 2000 has, by now, become well established globally (e.g. World Meteorological Organization (WMO) 2003, Chapter 4) and has led, over a period of a decade or so, to steadily increasing restrictions on the production of halogen-containing compounds. How ozone will behave in the near future has therefore become of major political significance. In particular, to establish whether the regulations in place are being effective, it is important to investigate the timing of the start of ozone recovery, both determined observationally and calculated with the use of numerical models. For example, a future delayed ozone recovery would not necessarily indicate that the emissions controls are ineffective, providing the simulations also show such a delay. On a longer timescale, complete ozone recovery, i.e. the return of ozone values to near the unperturbed atmospheric state, can only occur after halogen levels have substantially reduced. Although the Antarctic ozone hole is expected to disappear by about 2050 (e.g. Shindell et al. 1998; Nagashima et al. 2002) the vertical distribution of ozone could be very different to that which occurred two decades ago, before substantial anthropogenic losses began.

Ozone depletion is of major importance in the polar regions. The Antarctic ozone hole has a large impact on surface ultraviolet (UV) levels (e.g. Herman et al. 1996) and, in the Arctic, large ozone losses (e.g. Goutail et al. 1999) have the potential for

* Corresponding author, present address: Geophysical Fluid Dynamics Laboratory, 201 Forestal Road, Plainsboro, NJ 08542-0308, USA.e-mail: john.austin@ noaa.gov

(c) Crown copyright, 2003. 
increasing UV levels locally. Also, by the advection of low ozone amounts to midlatitudes, high-population regions could be affected (e.g. Austin et al. 1999). To investigate these issues requires coupled chemistry-climate models, as simpler models are unable to represent all the likely atmospheric interactions in a sufficiently realistic manner. Results of climate change experiments using eight coupled chemistry-climate models (Austin et al. 2003) indicated that, in the polar regions, the start of ozone recovery was likely to be delayed beyond the peak in atmospheric chlorine loading. This indicated that some other process, such as increases in well-mixed greenhouse gases (WMGHGs), may have contributed to the delay. This delay varied from model to model and was up to 7 years in the Antarctic, but as much as 18 years in the Arctic. One model, the results of which are described in detail here, gave delays of about 4 years and 14 years respectively.

The Unified Model with Eulerian Transport and Chemistry (UMETRAC) has recently been run in transient climate mode for the period 1979 to 2000, and comparisons were made with observed trends in temperature, ozone and water vapour (Austin 2002). In that simulation, Rayleigh friction was included in the stratosphere to decelerate the polar-night jet. However, in common with many other general-circulation models (see, e.g., Pawson et al. 2000), this led to a polar-night jet that was too strong, with an associated cold bias. The simulation of Austin (2002) has now been extended to the year 2020 and a further simulation for the period 1975 to 2020 has been completed with the Rayleigh friction replaced by a spectral gravity-wave forcing scheme (Scaife et al. $2000 \mathrm{~b})$. In this paper, the results of the two simulations are compared, to investigate temperature and ozone trends as well as the likely timing of the start of ozone recovery.

\section{MODEL DESCRIPTION AND INTEGRATIONS PERFORMED}

UMETRAC is based on the Met Office's Unified Model (UM), which has been used in the Intergovernmental Panel on Climate Change (IPCC) assessments (e.g. IPCC, 2001). UMETRAC has 64 vertical levels, from the ground to $0.01 \mathrm{hPa}$, and has a latitude-longitude resolution of $2.5^{\circ} \times 3.75^{\circ}$. The model includes a coupled stratospheric chemistry scheme involving 13 advected tracers $\left(\mathrm{O}_{3}, \mathrm{HNO}_{3}, \mathrm{~N}_{2} \mathrm{O}_{5}, \mathrm{HNO}_{4}\right.$, $\mathrm{HCl}(\mathrm{g}+\mathrm{s}), \mathrm{HOCl}, \mathrm{ClONO}_{2}, \mathrm{HOBr}, \mathrm{HBr}, \mathrm{BrONO}_{2}, \mathrm{H}_{2} \mathrm{O}_{2}, \mathrm{H}_{2} \mathrm{CO}$, Tracer-1). Tracer-1 is used to parametrize the long-lived species and families $\mathrm{H}_{2} \mathrm{O}, \mathrm{CH}_{4}, \mathrm{Cl}_{y}, \mathrm{Br}_{y}$, $\mathrm{H}_{2} \mathrm{SO}_{4}$ and $\mathrm{NO}_{y}$, where $\mathrm{Cl}_{y}=\mathrm{Cl}+\mathrm{ClO}+\mathrm{HCl}(\mathrm{g}+\mathrm{s})+\mathrm{HOCl}+\mathrm{ClONO}_{2}+2 \mathrm{Cl}_{2} \mathrm{O}_{2}$ $+\mathrm{BrCl}, \mathrm{Br}_{y}=\mathrm{Br}+\mathrm{BrO}+\mathrm{HBr}+\mathrm{BrONO}_{2}+\mathrm{HOBr}+\mathrm{BrCl}$, and $\mathrm{NO}_{y}=\mathrm{NO}+\mathrm{NO}_{2}$ $+\mathrm{NO}_{3}+\mathrm{HNO}_{3}(\mathrm{~g}+\mathrm{s})+2 \mathrm{~N}_{2} \mathrm{O}_{5}+\mathrm{HNO}_{4}+\mathrm{ClONO}_{2}+\mathrm{BrONO}_{2}$. In the above $(\mathrm{g}+\mathrm{s})$ is used to denote the sum of concentrations in the gas ( $\mathrm{g}$ ) and solid (s) phases. A simplified sedimentation scheme is included and the Polar Stratospheric Cloud (PSC) scheme is based on liquid ternary solutions (LTS) (Carslaw et al. 1994) and ice or nitric acid trihydrate (NAT) and water ice. The photochemistry therefore explicitly includes all the major processes affecting stratospheric ozone. Reaction rates are taken from DeMore et al. (1997) and Sander et al. (2000). Sea surface temperatures and sea ice are specified from observations (1980-2000), with the future trend specified from simulations of a coupled ocean-atmosphere version of the model of Williams et al. (2001). In the standard model, Rayleigh friction is used to decelerate the polar night jet and an alternative version is available with a spectral gravity-wave forcing scheme (Scaife et al. 2000b). Halogen amounts are specified according to WMO (1999, Table 12-2), and the WMGHG concentrations $\left(\mathrm{CO}_{2}, \mathrm{CH}_{4}, \mathrm{~N}_{2} \mathrm{O}, \mathrm{CFC} 11\right.$ and $\mathrm{CFC} 12$ are specified according to IPCC scenario IS92a (IPCC, 1992)). The concentrations of the WMGHGs and of the long-lived tracers are given in Table 1. 


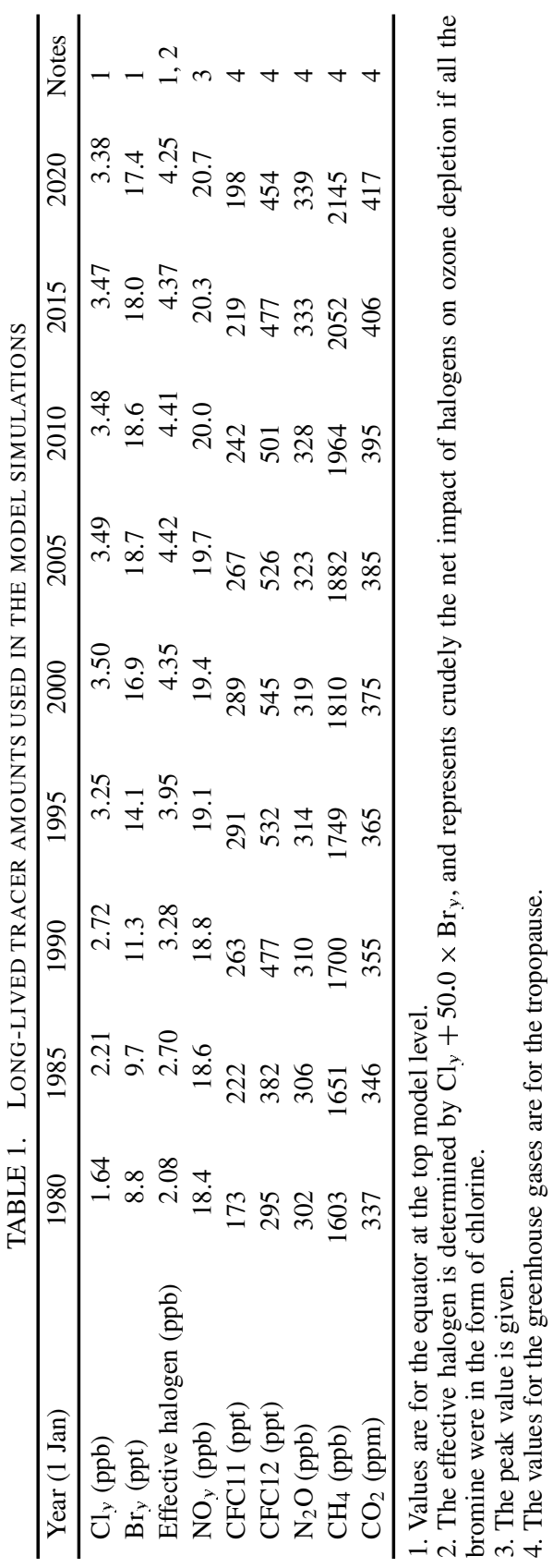


TABLE 2. SUMMARIES OF THE MODEL SIMULATIONS PRESENTED IN THIS WORK. ALL THE RUNS ARE TRANSIENT CLIMATE RUNS WITH STEADILY EVOLVING GREENHOUSE GASES AND LONG-LIVED CHEMICAL SPECIES. $\Delta T$ IS THE TEMPERATURE PERTURBATION TO THE HETEROGENEOUS CHEMISTRY SCHEME.

\begin{tabular}{lccccc}
\hline Run & Dynamics & $\begin{array}{c}\text { Heterogeneous } \\
\text { chemistry }\end{array}$ & $\Delta T$ & Period & Reference \\
\hline RF & Rayleigh Friction & NAT/ice & $5 \mathrm{~K}$ & $1979-2020$ & Austin (2002) + this work \\
GWF & Spectral gravity-wave & LTS/ice & $0 \mathrm{~K}$ & $1975-2020$ & This work \\
& forcing & & & & Butchart et al. (2000) \\
GHG & Rayleigh Friction & No chemistry & - & $1992-2051$ & But \\
\hline
\end{tabular}

Simulations have been completed for the periods March 1979 to January 2020 (Rayleigh friction, hereafter referred to as 'run RF') and January 1975 to January 2020 (spectral gravity-wave forcing, hereafter referred to as 'run GWF'). The results of the model for run RF covering the period January 1980 to December 1999 are described in Austin (2002). In this paper we describe the results of the extension of run RF and of the new run GWF. In addition to the dynamical differences indicated above, in run RF the temperatures were increased by $5 \mathrm{~K}$ inside the heterogeneous chemistry routines. This was done to reduce the unrealistic activation of chlorine and bromine with consequent ozone depletion. At least one other model uses a similar technique, as described in Austin et al. (2003). In the chemistry-climate model of Hein et al. (2001), the need to increase the temperatures is interpreted as a nucleation barrier for the formation of PSCs. The model of Manzini et al. (2003) uses a gravity-wave forcing scheme and does not have a nucleation barrier, and it is argued that hypothetical subgridscale processes would be sufficient to trigger PSCs.

With the reduced temperature biases in run GWF no adjustment was made and, moreover, the PSC scheme was changed from NAT/ice to use the alternative LTS/ice chemistry. Comparisons are also made, where appropriate, with a 60-year climate experiment also run with the UM (Butchart et al. 2000). This is the core climate model in which the chemistry of UMETRAC is run and has a fixed ozone climatology based on the current atmosphere. A summary of these runs is indicated in Table 2.

\section{ANALYSIS OF RESULTS: TEMPERATURE}

\section{(a) Model bias}

Temperature biases can have a significant impact on the model-simulated ozone, particularly in the polar regions when heterogeneous chemistry is operating, as noted, for example, in Austin et al. (2003). For run RF, Austin (2002, Fig. 11) showed there were substantial cold biases over both poles during winter and spring. Including the spectral gravity-wave parametrization in run GWF increases the temperatures in high latitudes throughout the year and throughout the depth of the stratosphere compared with run RF (see Fig. 1) and deceases the biases substantially (Fig. 2).

At $1 \mathrm{hPa}$ the largest effects are in early and late winter in both hemispheres. Generally, throughout winter and spring, run GWF has a much warmer South Pole than run RF. On descending through the stratosphere the greatest differences between the two runs in South Pole temperatures occurs progressively later in the year - September at $1 \mathrm{hPa}$ (where the difference exceeds $30 \mathrm{~K}$ ), October at $10 \mathrm{hPa}$ and then December at $46 \mathrm{hPa}$. This is because the inclusion of the spectral gravity-wave parametrization not only reduces the model's cold pole bias, as well-documented by other authors (e.g. Manzini and McFarlane 1998; Scaife et al. 2002), but it also improves the timing of 
(a)

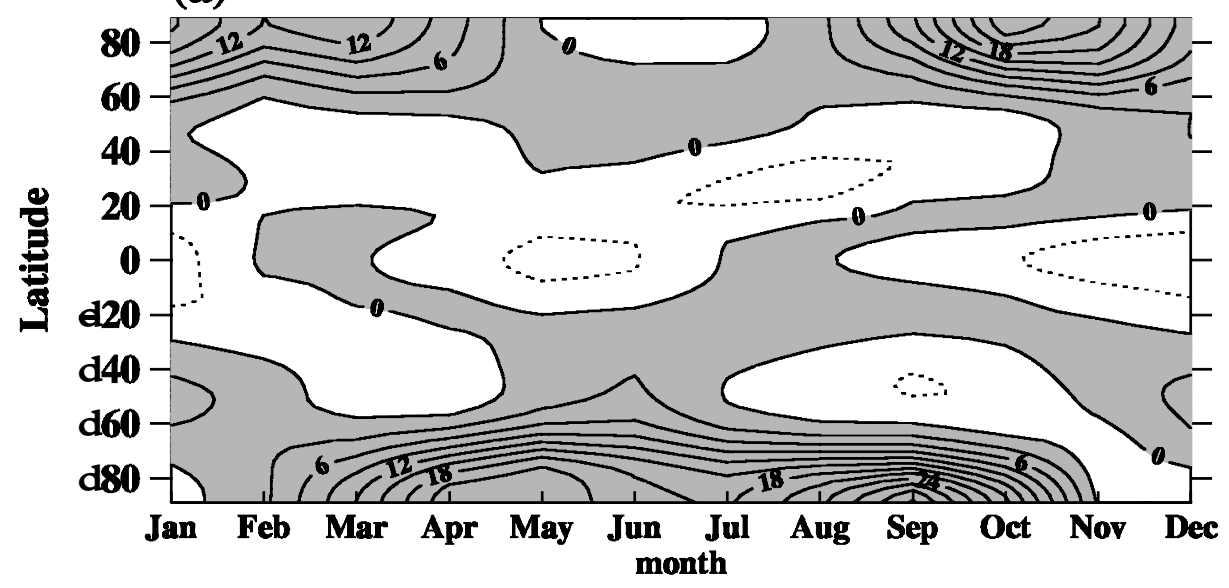

(b)

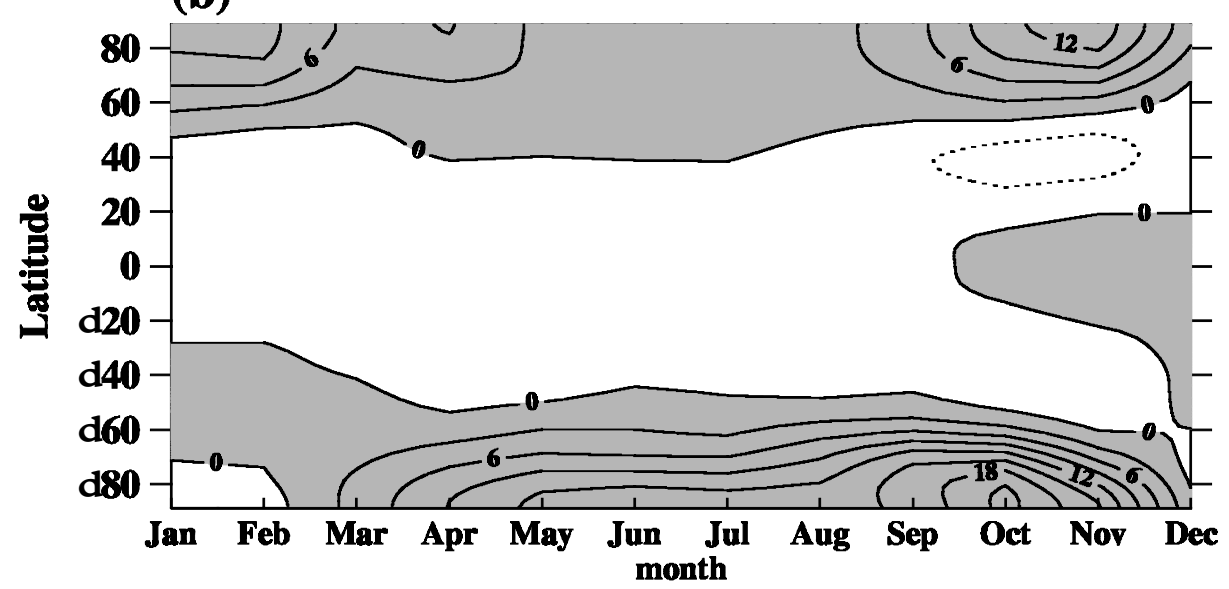

(c)



Figure 1. Differences in model temperature climatologies (Gravity-Wave Forcing minus Rayleigh Friction runs) at selected levels as a function of latitude and month. The shaded region indicates positive values. The contour interval is $3 \mathrm{~K}$. (a) $1 \mathrm{hPa}$, (b) $10 \mathrm{hPa}$ and (a) $46.4 \mathrm{hPa}$. 
(a)

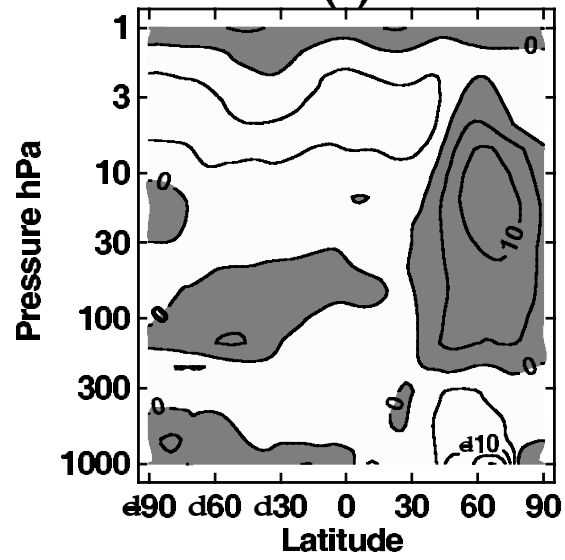

(c)

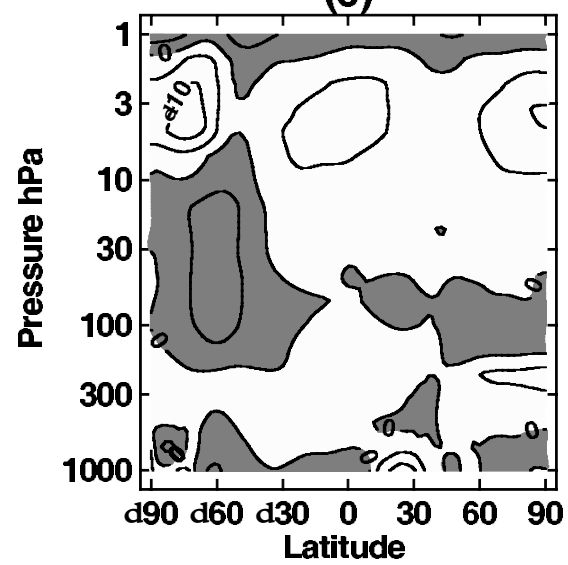

(b)

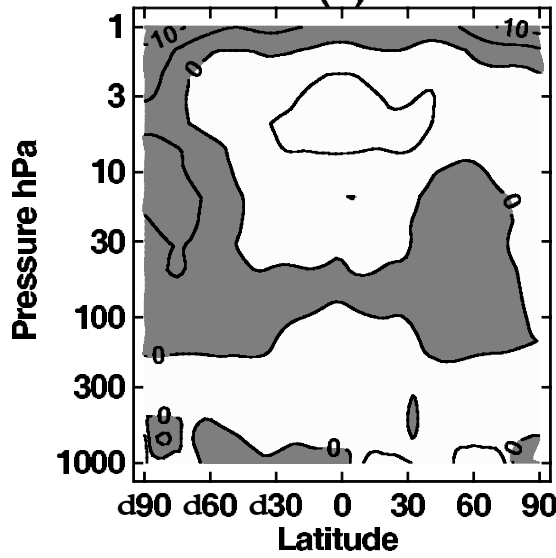

(d)

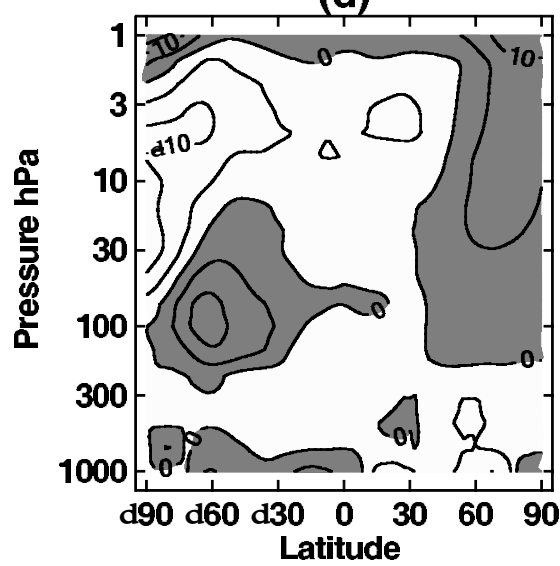

Figure 2. Difference between the temperature climatology for Gravity-Wave Forcing run and observations from Met Office data assimilation fields (Swinbank and O'Neill 1994) for the period 1991 to 2000 for the four seasons: (a) Dec. to Feb, (b) Mar. to May, (c) Jun. to Aug. and (d) Sep. to Nov. Shaded regions denote where the model climatology is warmer than observations. The contour intervals is $5 \mathrm{~K}$.

the breakdown of the southern hemisphere vortex (Scaife et al. 2002). At the South Pole there is still a cold bias in run GWF (Fig. 2) which exceeds $10 \mathrm{~K}$ between 40 and $4 \mathrm{hPa}$ during the spring. In the absence of any temperature adjustments in the heterogeneous chemistry, this would tend to affect the activation of chlorine and bromine in the model and distort the shape and depth of the simulated Antarctic ozone hole. This would lead to excessive depletion at higher levels and insufficient depletion in lower levels away from the pole.

Over northern high latitudes during winter, a warm bias is present in both runs in the middle and lower stratosphere. This would tend to reduce (or indeed eliminate) the loss of ozone via heterogeneous chemistry in the earlier part of the season. By the time of the main ozone depletion period in spring, the bias is somewhat smaller.

\section{(b) Globally averaged temperature trends}

The globally and annually averaged temperatures for the two coupled chemistryclimate experiments are shown in Fig. 3, together with results from Butchart et al. (2000) 
(a)

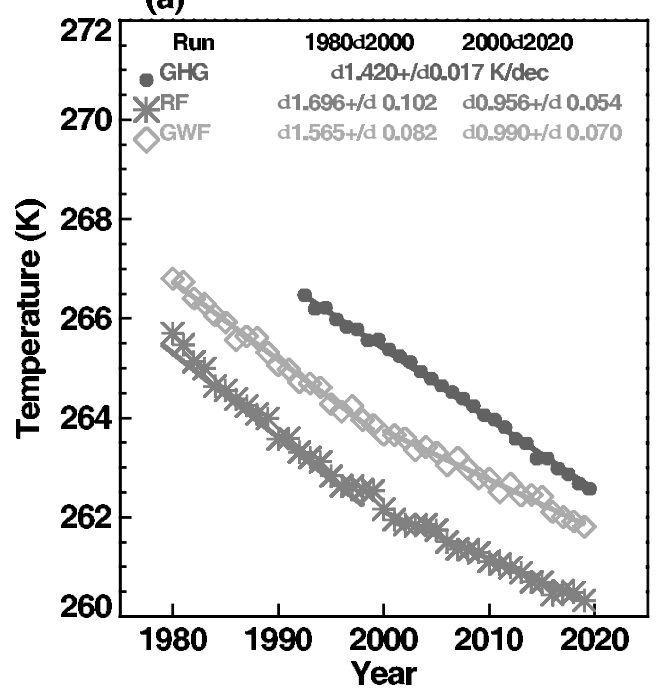

(c)

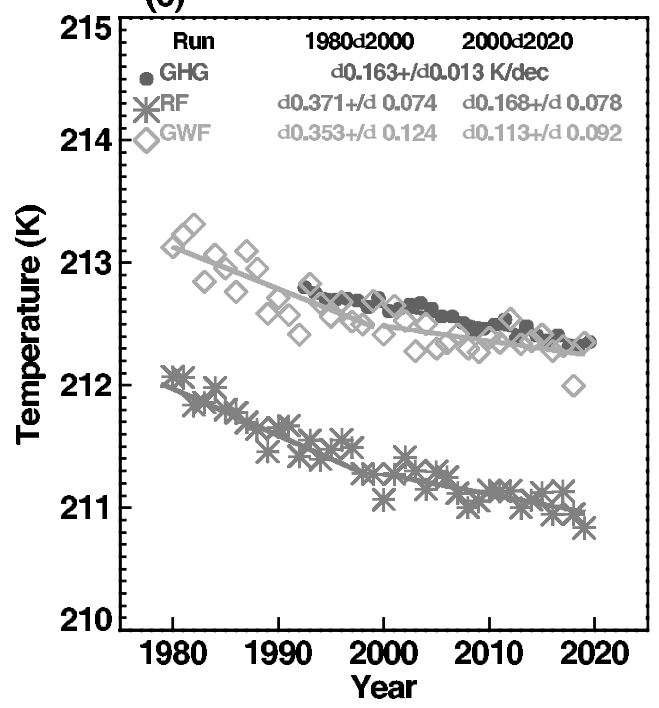

(b)

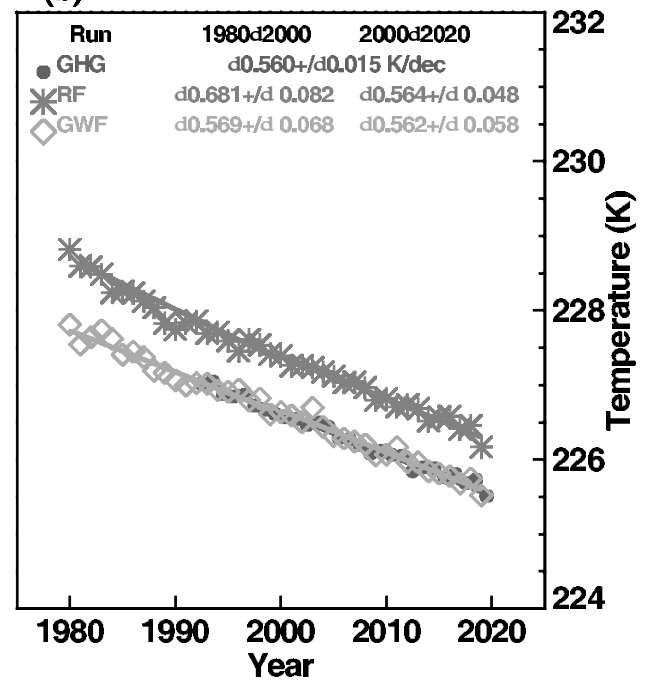

(d)

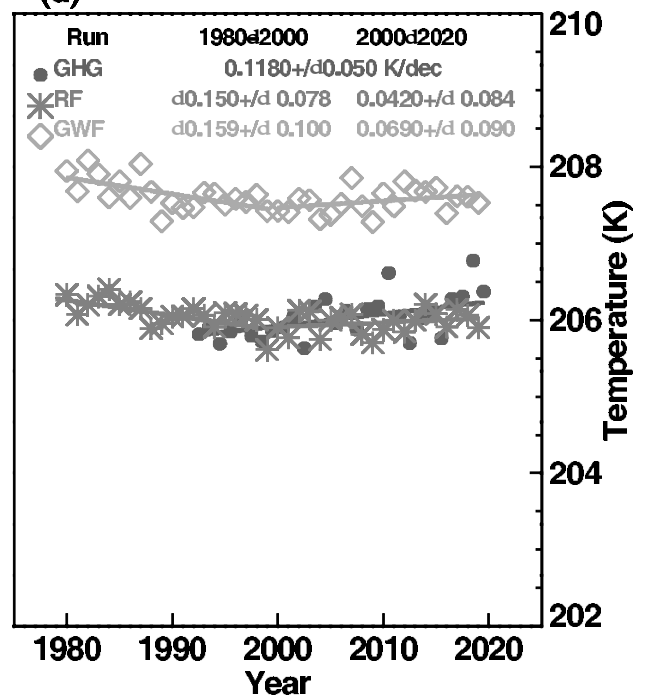

Figure 3. Globally and annually averaged temperatures at selected pressure levels (a) $1 \mathrm{hPa}$, (b) $10 \mathrm{hPa}$, (c) $46 \mathrm{hPa}$ and (d) $100 \mathrm{hPa}$, from the two coupled chemistry-climate model runs (Rayleigh Friction, RF, and Gravity-Wave Forcing, GWF) in comparison with the climate model run of Butchart et al. (2000), GHG. For clarity, the results for run RF have been shifted down the ordinate by $1.0 \mathrm{~K}$ at all levels except at $10 \mathrm{hPa}$, where the RF results have been shifted up by $1.0 \mathrm{~K}$. The calculated trends are given for the two separate periods, except for run GHG, which is a mean trend for the whole period.

for a climate experiment with changing WMGHGs. For run RF, the trend is slightly different to that published in Austin (2002) due to the different order in computing the trend and the spatial and temporal averaging. One of the most noticeable aspects of the RF and GWF runs is the change in trend between the first half of the runs and the second half. In contrast, the GHG run indicates no such change. This is to be expected because of the different ozone trend in the two periods for the coupled chemistry simulations (see below). Therefore in each panel, the mean temperature trends of the RF and GWF 
(a)

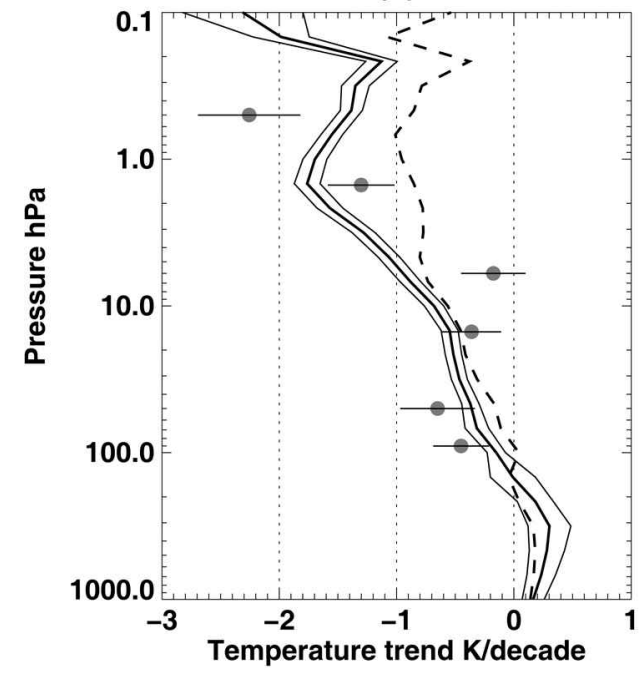

(b)

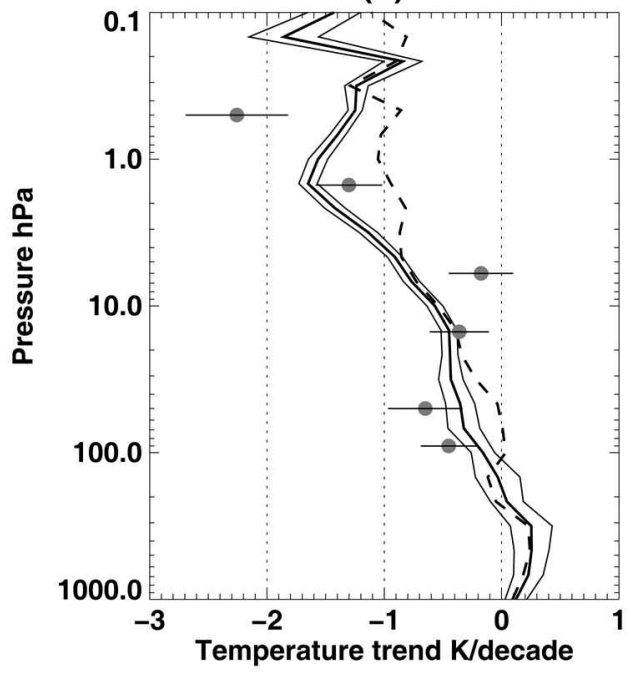

Figure 4. Globally and annually averaged temperature trend as a function of pressure. The filled circles and uncertainty ranges indicate the trend and estimated $2 \sigma$ uncertainty from the satellite and microwave sounding unit observations over the period Jan. 1979 to Dec. 1997 with the solar cycle removed. The thick solid lines indicate the model trends for the period Jan. 1980 to Dec. 1999 and the thin solid lines are the 95\% confidence intervals. Broken lines indicate the model trends for the period Jan. 2000 to Dec. 2019. (a) Rayleigh Friction run and (b) Gravity-Wave Forcing run.

runs are given for each of the two period January 1980 to December 1999 and January 2000 to December 2019. The change in trend is particularly large at $1 \mathrm{hPa}$, where the $\mathrm{RF}$ and GWF cooling trend decreases from about $1.6 \mathrm{~K} /$ decade to about $1.0 \mathrm{~K} /$ decade. At $10 \mathrm{hPa}$, the temperature trend does not change during the 40 -year simulations, and the cooling rates are close to those computed in run GHG, which had no ozone change. In the lower stratosphere, the temperature trends in runs RF and GWF change from a noticeable cooling to just a slight cooling, or even a slight warming at $100 \mathrm{hPa}$ in the second half of the runs. The differences in the trends are statistically significant at the $95 \%$ confidence level, at all the atmospheric pressures indicated except $10 \mathrm{hPa}$.

The calculated trends for run RF agree with those from run GWF, within the uncertainties. This, combined with previous results of the model (Austin 2002), suggests that the trends arise from changes in the external parameters (WMGHGs, halogens, sea surface temperatures) rather than model internal variability. This internal variability is indicated by the variability in the results from individual years which, as noted in Austin et al. (2003), is generally larger in the GWF run.

Comparisons of the model-simulated trends with those observed from satellite and microwave sounding unit data (Scaife et al. 2000a) are shown in Fig. 4. Consistent with the results of other models noted in Shine et al. (2003), the RF and GWF runs agree broadly with the satellite data, except possibly near $10 \mathrm{hPa}$ and above $1 \mathrm{hPa}$. As noted above, the model indicates a different trend in the two periods in the lower and upper stratosphere, but the trends do not change substantially in the middle stratosphere $(8-20 \mathrm{hPa})$. Figure 4 suggests that, if one were concerned with the detection and attribution of atmospheric change, the upper stratosphere is the best region to investigate. These results are consistent with the model ozone trends (see section 4) and the results of Shine et al. (2003) which demonstrate a sensitivity to ozone trends in the lower and upper stratosphere, but not in the middle stratosphere. 

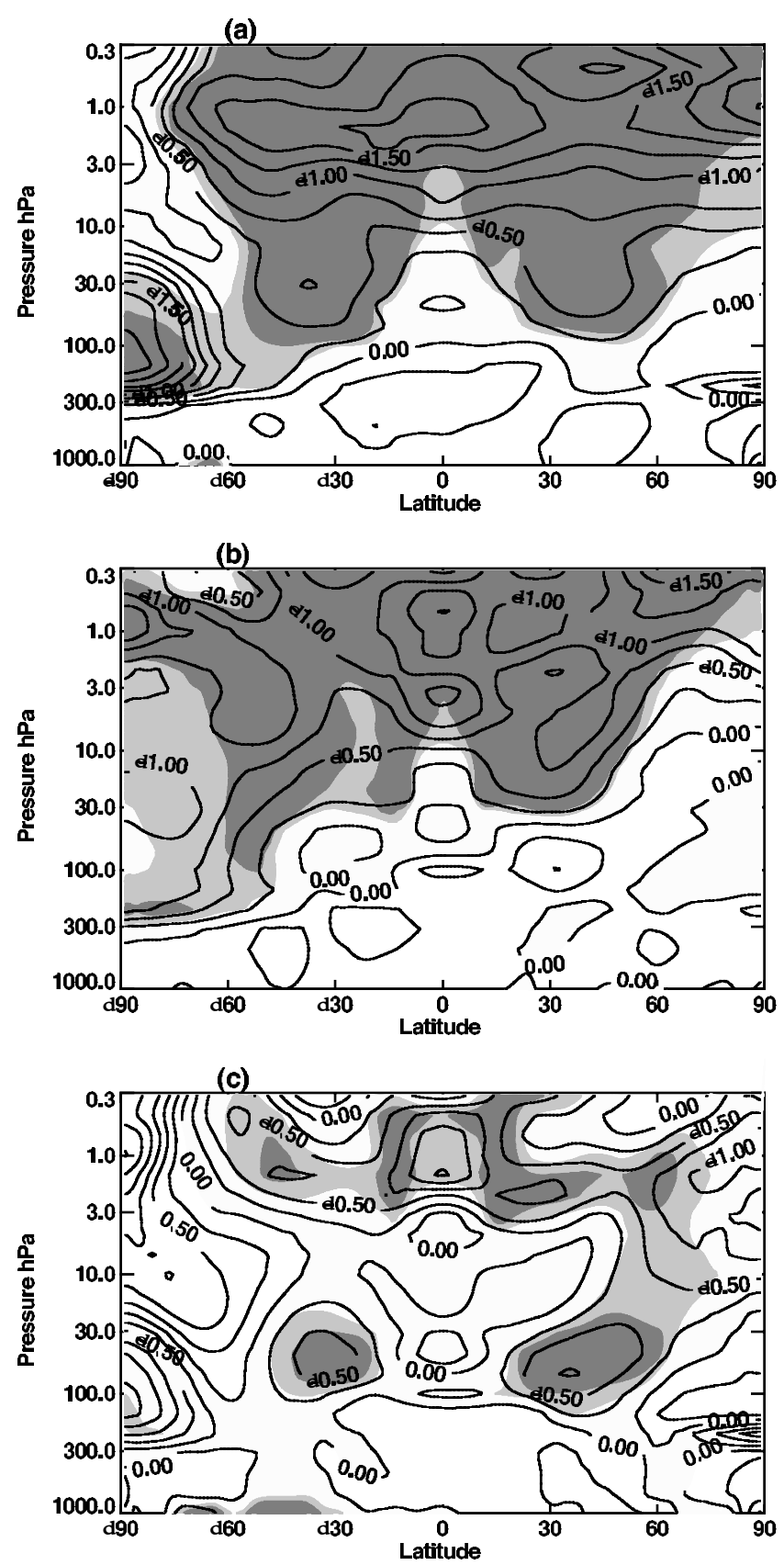

Figure 5. Annually averaged temperature trend from the Gravity-Wave Forcing run as a function of pressure and latitude. (a) Jan. 1980 to Dec. 1999, (b) Jan. 2000 to Dec. 2019 and (c) difference in trends. In (a) and (b), the dark and light shading indicates where the cooling is statistically significantly at the $95 \%$ and $80 \%$ levels. In (c), the shaded region indicates where the trend for the first half of the integration is significantly different from that in the second half. The contour interval is $0.25 \mathrm{~K} / \mathrm{decade}$. 


\section{(c) Latitudinally varying temperature trends}

The annual mean trends as a function of latitude for the GWF experiment are shown in Fig. 5. Similar results were obtained for run RF (Austin 2002, Fig. 12) although there was slightly less interannual variability in that run compared with GWF. The cooling is statistically significant at the $95 \%$ level over both halves of the simulation, as indicated by the deep shading in Fig. 5. However, there is a band in the tropics extending almost as high as $3 \mathrm{hPa}$ in which, in contrast to run RF, the cooling is not statistically significant. The reduction in statistical significance is due to the higher interannual variability in run GWF, most of which is probably related to the quasi-biennial oscillation, which is present in the simulation (Butchart et al. 2003), but has not been allowed for in the trend analysis. There is also significant cooling in the lower stratosphere over Antarctica, which is probably related to the ozone hole. The cooling trend there is much less during the second half of the integration. Figure 5(c) shows the difference between the temperature trends with the shading indicating statistical significance at the $80 \%$ and $95 \%$ levels, using a two-tailed t-test. This indicates that if each latitude and height point is treated independently, the interannual variability in the temperatures is too large for the difference to be statistically significant. Nonetheless, examination of the temperature trends over Antarctica suggests a strong connection with ozone (see Austin 2002, Fig. 14) during spring. This connection would be expected to change for the two halves of the simulations. For run RF the November trend difference (1980-99 minus 2000-19), averaged over the main ozone hole region $75^{\circ}$ to $90^{\circ} \mathrm{S}$ and 30 to $150 \mathrm{hPa}$, is $-5.4 \pm 4.4(2 \sigma)$, compared with $-6.5 \pm 8.9 \mathrm{~K} /$ decade for run GWF. Thus, although there is a statistically significant difference in the RF run, and the two runs agree reasonably well, the larger interannual variability noted in Austin et al. (2003) has reduced the statistical significance to about the $80 \%$ level.

\section{ANALYSis OF RESULTS: OZONE}

\section{(a) Globally averaged total ozone}

Globally averaged total ozone from the model is shown in Fig. 6, in comparison with Total Ozone Mapping Spectrometer (TOMS) data. The solar cycle has a well-known impact on total ozone (e.g. Zerefos et al. 1997) and is also shown in the figure. Both the data and model runs indicate a downward trend up to about the year 2000 and thereafter both model runs show a very slight rise. The model simulations show very similar overall features. For the period January 1980 to December 1999 , the annually averaged global trends in the model are $-3.6 \pm 0.6 \mathrm{DU} / \mathrm{decade}$ for run RF and $-6.1 \pm 1.3 \mathrm{DU} /$ decade for run GWF. The RF value is slightly different to that reported in Austin (2002) due to the different order of computing the trend and the averaging (spatial and temporal). The trends from both simulations are lager than observed $(-2.0 \pm 1.4$ DU/decade) although, as noted in Austin (2002), a small change is difficult to measure accurately because of the influence of the solar cycle and the change in satellite instrument through the period. However, the satellite data include a tropospheric component which may be increasing the total column by as much as approximately $1 \%$ of 3 DU per decade, which is not taken into consideration in the model because of the absence of a tropospheric chemistry scheme.

After 2000, the model trend is slightly upwards and both runs agree $(0.8 \pm$ 0.7 DU/decade for run RF and $0.9 \pm 0.5 \mathrm{DU} /$ decade for run GWF). 




Figure 6. Annual mean total ozone averaged over the latitude range $65^{\circ} \mathrm{N}$ to $65^{\circ} \mathrm{S}$ from Gravity-Wave Forcing (GWF) and Rayleigh Friction (RF) runs in comparison with Total Ozone Mapping Spectrometer (TOMS) data. The approximate impact of the 11-year solar cycle is indicated by the dashed line (solar flux). The results for run RF have been shifted down the ordinate by 20 DU for clarity.

\section{(b) Annually averaged ozone trends}

As noted in the case of both temperature and globally averaged ozone, the trends change from about 2000. Therefore, in Figs. 7 and 8 are shown the ozone trends for the two halves of simulations RF and GWF respectively. For the period January 1980 to December 1999, significant downward trends in ozone were simulated by both RF and GWF runs across a wide range of latitudes in the upper stratosphere. At $3 \mathrm{hPa}$, the peak midlatitude trend is about $6 \%$ per decade, very similar to that observed by the Stratospheric Aerosol and Gas Experiment (SAGE) (Randel and Wu 1999). This is related to increasing halogen amounts, and the comparison with observations indicates that these processes are quantitatively well understood. In the second half of the integrations, halogens decrease slowly and the simulated ozone increases significantly. In the past, statistically significant ozone decreases also occur over Antarctica due to the ozone hole, and this is much reduced during the second half of the simulations. The difference in the trends between the two halves of the run are also significantly different from zero in the same regions. For the past, both model runs compare favourably with observations (Randel and Wu 1999), as discussed for run RF by Austin (2002). The ozone trend for the past has a similar vertical and horizontal structure as the temperature trend (Fig. 5), indicating the probable importance of ozone trends in influencing the temperature. This is confirmed by Shine et al. (2003) for the global average using a variety of models. For the second half of the simulation, the ozone trend is somewhat smaller and the temperature trends are probably dominated more by the increases in the concentrations of the WMGHGs. Nonetheless, the reduction in temperature trend in the upper stratosphere and the reduction in temperature trend in the lower stratosphere over Antarctica, from the first to the second half of the runs, is consistent with the ozone changes. Further, the middle stratosphere ozone trend, which is quite small throughout the runs, is both consistent with the observed small ozone trends (Randel and Wu 

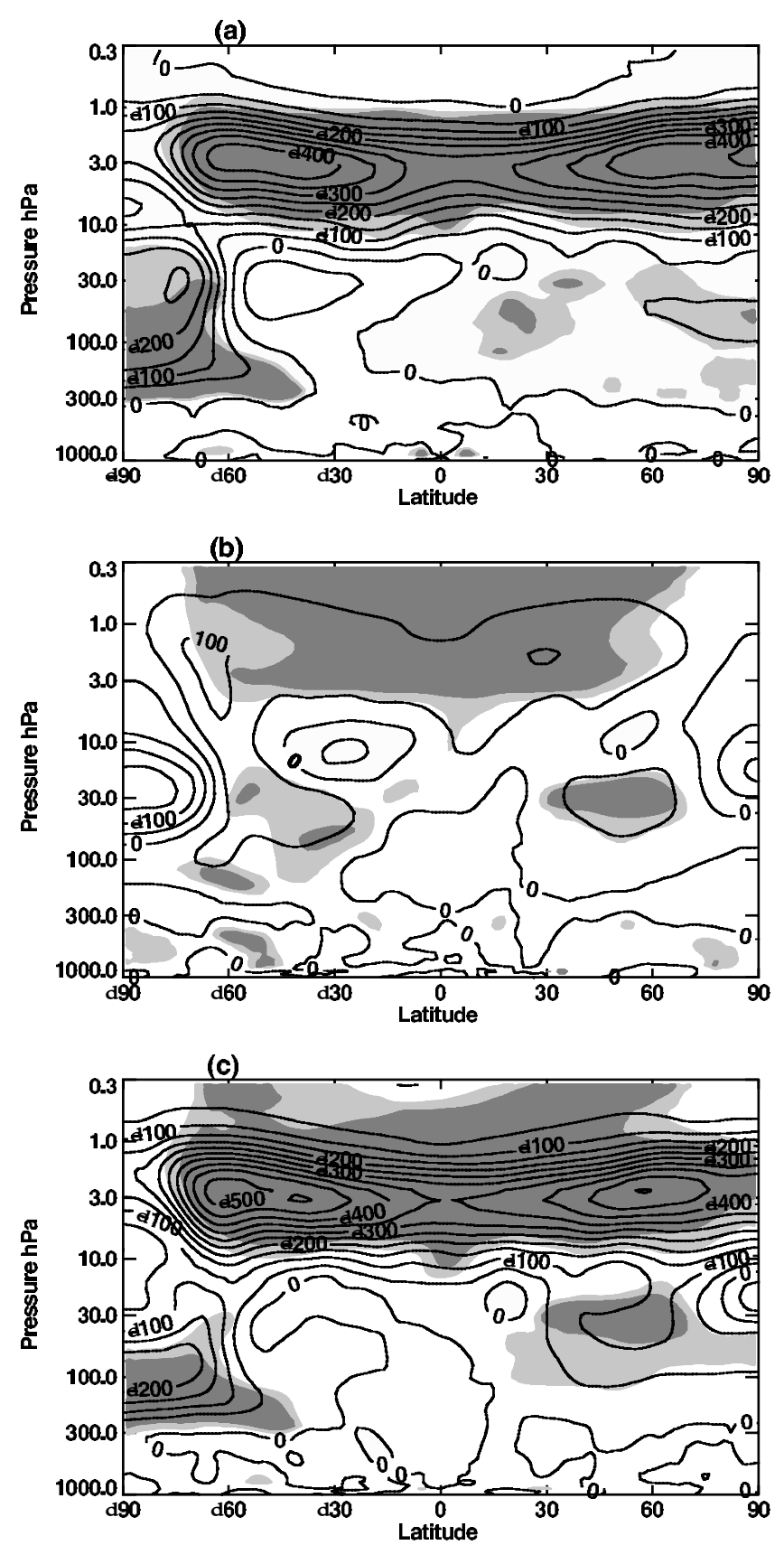

Figure 7. Annually averaged ozone trend from Rayleigh Friction run as a function of pressure and latitude. (a): 1980-99, with dark and pale shading indicating where the ozone trend is less than zero at the significance levels $95 \%$ and $80 \%$ respectively. (b): $2000-19$, with shaded regions indicating where the ozone trend is significantly greater than zero. (c): Difference in trends, with shaded region indicating where the trend for the first half of the integration is significantly lower than in the second half. The contour interval is $50 \mathrm{ppbv} / \mathrm{decade}$. 

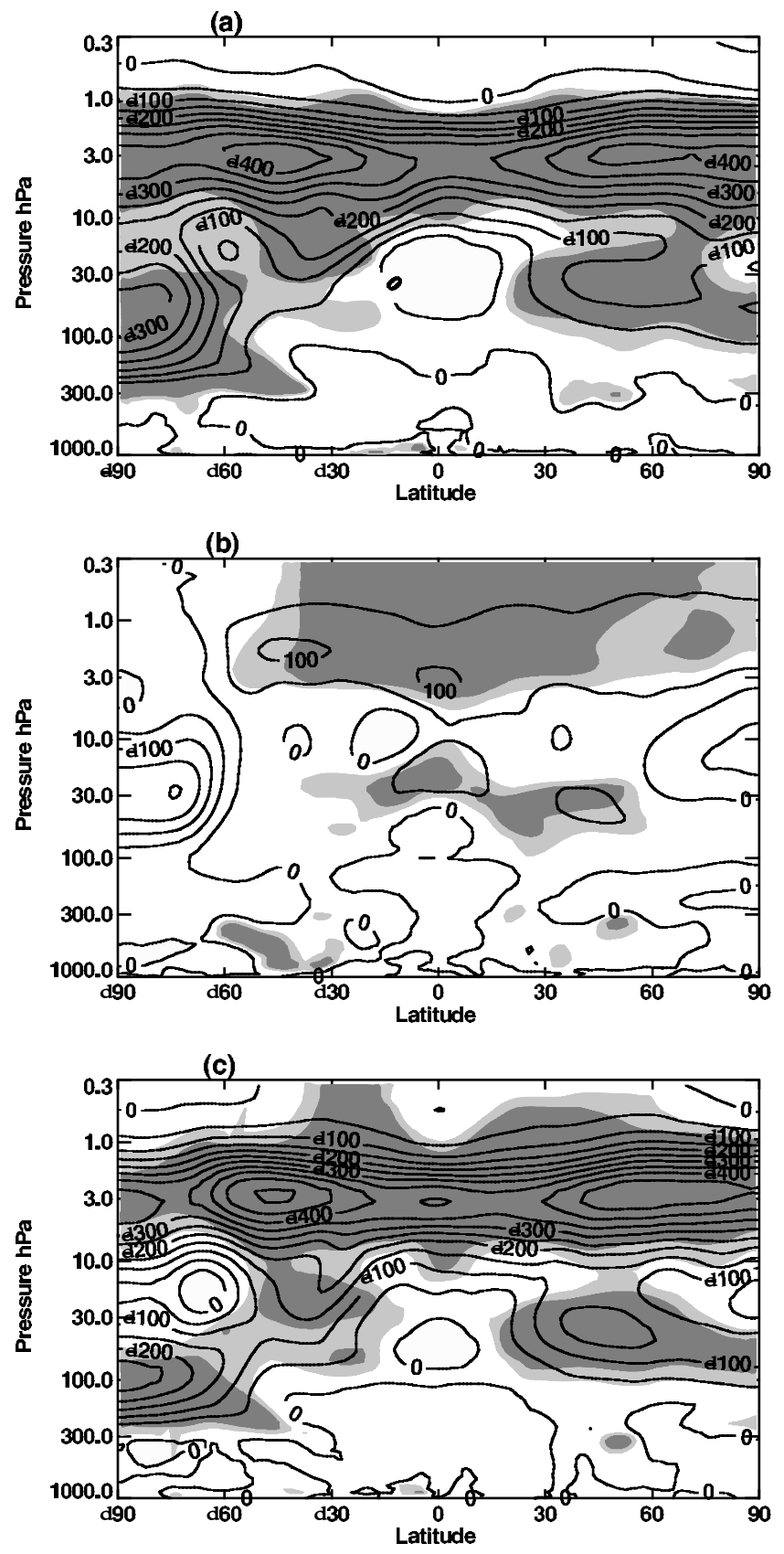

Figure 8. As Fig. 7, but for Gravity-Wave Forcing run. 
1999) and would tend to explain the insensitivity of the temperature trend in the middle stratosphere to the period chosen (see Fig. 3).

\section{THE START OF RECOVERY OF TOTAL OZONE}

As indicated in Fig. 6, globally averaged total ozone is simulated to decrease and then to start to increase from about the year 2000 or later. It is important to be able to simulate accurately the timing of the start of ozone recovery to establish whether the regulations in place to control ozone-depleting substances are being effective. In practice the detection of trends, and hence establishing the timing of recovery, is hampered by a number of factors including interannual variability (e.g. Weatherhead et al. 1998). This suggests the need for many years of observations or model results to reduce the statistical noise. Therefore in this work we use decadally smoothed values, with onesided averages at the beginning and end, to try to establish the start of ozone recovery or, equivalently, the year of the minimum in total ozone.

\section{(a) The recovery of regionally averaged total ozone}

Typically, model ozone trends were largest in March in the northern hemisphere and October in the southern hemisphere and, to investigate the results in more detail, the model results have been separated into $30^{\circ}$ latitude bands (Fig. 9 for run RF and Fig. 10 for run GWF). The runs produce similar results. As in the globally averaged ozone, the regionally averaged ozone decreases during the first twenty years of the integrations. This is particularly noticeable over the Antarctic during October, but this decrease is not significant over the Arctic during March. A quantitative comparison with TOMS data of the past trends is indicated in Table 3. For March and October, the agreement with TOMS is generally better for run GWF than for run RF. This is probably due to the reduced temperature bias, which has enabled a realistic run to be completed without a temperature correction in the heterogeneous chemistry scheme. Nonetheless, the trend in run GWF for the Arctic in March is still only about two thirds that observed. Run GWF also indicates a significant trend in northern midlatitudes, in contrast to run RF. However, the trend in the tropics in run GWF, particularly in the annual average, is not consistent with TOMS data. Comparisons with SAGE data (D. Cunnold, personal communication, 2002) suggests that the stratospheric column has decreased in the tropics by about $1 \%$ per decade, similar to that in run GWF, and this decrease could have become masked in the TOMS data by a tropospheric column increase. In comparison, the simulations here relax ozone towards fixed values in the troposphere and so do not strictly include the tropospheric trend. In the southern hemisphere during October, the substantial ozone loss over Antarctica appears in the trends and, in contrast to run RF, there is also a smaller midlatitude loss in run GWF, which is in better agreement with the TOMS data. In the winter season there is a loss of ozone as shown by Roscoe et al. (1997). The TOMS data analysed here give $-17 \pm 6 \mathrm{DU} /$ decade for July which is reproduced by run GWF $(-13 \pm 6)$ but is not reproduced by run $\mathrm{RF}(-3 \pm 8)$. Note that trends both in the TOMS data and in the model runs vary substantially depending on the period chosen. Adding one or two years of additional data to the period over which the trend is computed can substantially affect the results obtained, as indicated by the (generally) large uncertainties in the quoted trends. These differences arise from atmospheric and model internal variability as well as variability in the imposed sea surface temperatures and ice amount. Also the physical processes responsible for the trends are themselves evolving, causing a systematic change in the trends. For example, taking the period of the trends to the end of year 2001 decreases the size of the TOMS 

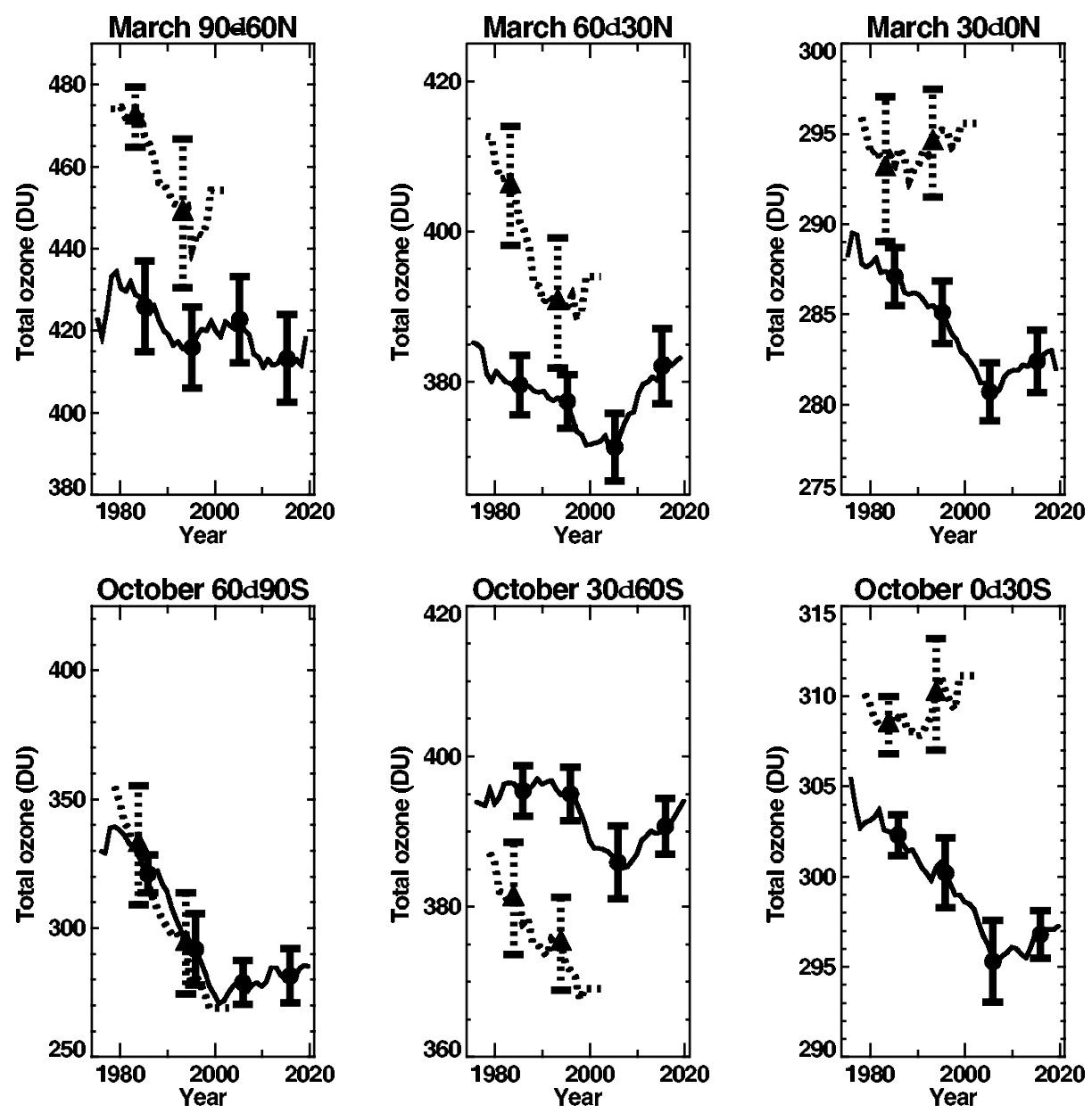

Figure 9. Decadally smoothed ozone valued averaged over selected latitude bands (mass weighted) as a function of time for March and October. The results for the Rayleigh Friction run are indicated by solid lines, solid uncertainty ranges and filled circles. The Total Ozone Mapping Spectrometer (TOMS) Version 7 data are indicated by dotted lines, dotted uncertainty ranges and filled triangles. The TOMS data have been shifted up the ordinate by $30 \mathrm{DU}$ to enable trends to be seen more readily. The uncertainty ranges denote the $95 \%$ confidence intervals for the decadal average values.

trend in October in the Antarctic to just $36 \pm 12$ DU/decade and reduces the size of the Arctic March trend to $22 \pm 16$ DU/decade. The Arctic result is likely strongly affected by interannual variability, although with many of the recent winters having been relatively warm, thee is a slight hint of a systematic change. The Antarctic result reflects the near-constant intensity of the ozone hole since the early 1990s. The trends will also vary slightly according to the method used to remove the solar cycle from the TOMS data, which are here multi-linearly regressed against time and the annual mean solar flux at a wavelength of $10.7 \mathrm{~cm}$.

After the year 2000, the only region where significant recovery occurs in the model simulations (Figs. 9 and 10) is in northern midlatitudes. Even over Antarctica, ozone recovery is slow or non-existent. The lowest ozone is typically reached in the year 2005 but, except for northern midlatitudes, the curves in Figs. 9 and 10 are virtually flat from 

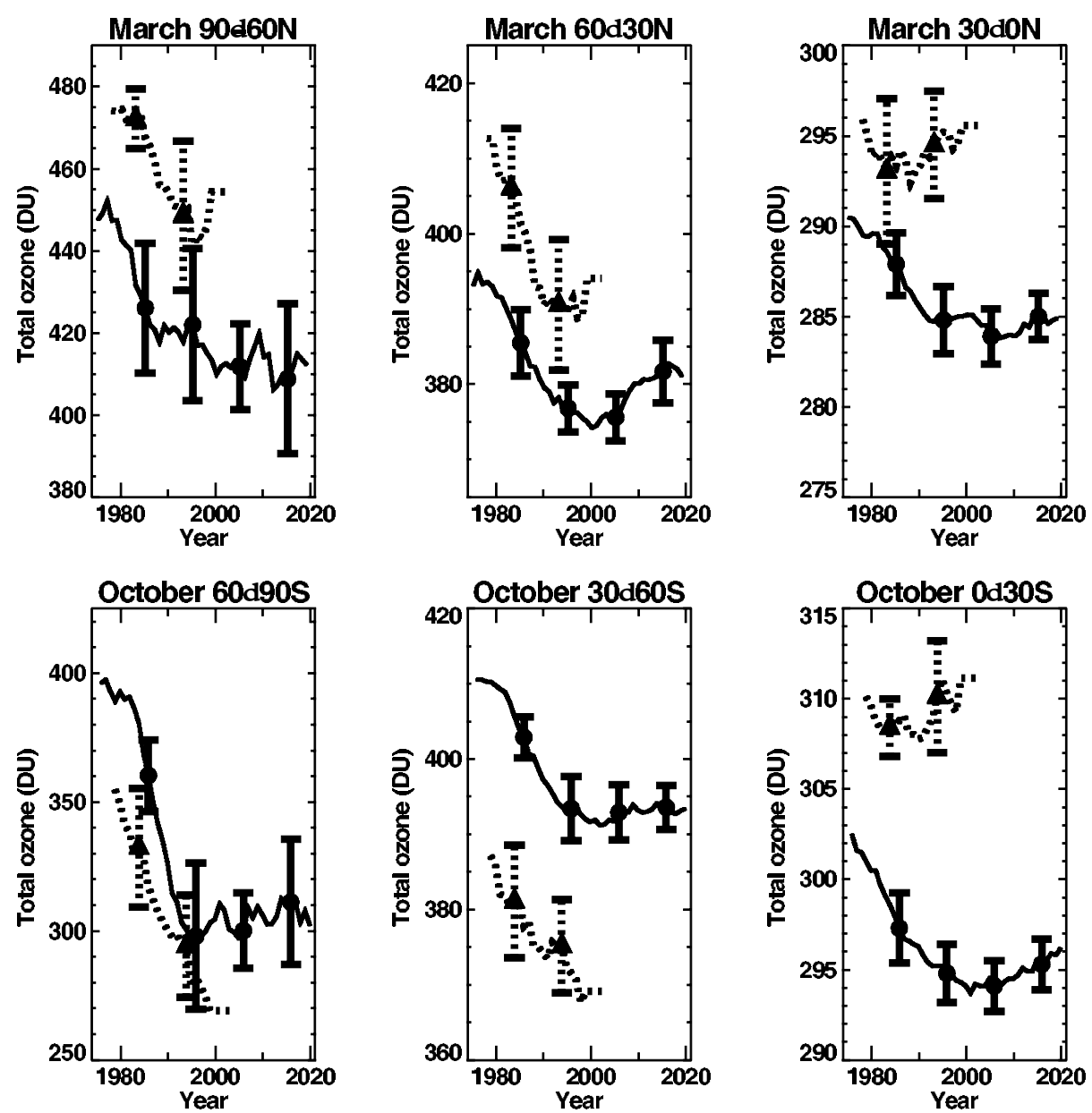

Figure 10. As Fig. 9, but for Gravity-Wave Forcing run.

TABLE 3. OZONE TRENDS, WITH 95\% CONFIDENCE INTERVALS, IN THE MODEL SIMULATIONS (DU/DECADE) FOR THE PERIOD JANUARY 1979 TO DECEMBER 1999 COMPARED WITH TOMS DATA, AFTER REMOVING THE SOLAR CYCLE

\begin{tabular}{lcccc}
\hline Month & \multicolumn{1}{c}{ Zone } & Trend run RF & Trend run GWF & TOMS trend \\
\hline March & $60^{\circ}-90^{\circ} \mathrm{N}$ & $-8 \pm 13$ & $-17 \pm 20$ & $-24 \pm 20$ \\
& $30^{\circ}-60^{\circ} \mathrm{N}$ & $-2 \pm 4$ & $-10 \pm 5$ & $-14 \pm 10$ \\
& $0^{\circ}-30^{\circ} \mathrm{N}$ & $-1.5 \pm 1.8$ & $-2.1 \pm 1.8$ & $-1.2 \pm 4.3$ \\
\hline October & $60^{\circ}-90^{\circ} \mathrm{S}$ & $-36 \pm 14$ & $-60 \pm 24$ & $-53 \pm 18$ \\
& $30^{\circ}-60^{\circ} \mathrm{S}$ & $0 \pm 4$ & $-11 \pm 4$ & $-10 \pm 7$ \\
& $0^{\circ}-30^{\circ} \mathrm{S}$ & $-1.1 \pm 1.9$ & $-2.7 \pm 1.6$ & $+1.3 \pm 2.9$ \\
\hline July & $60^{\circ}-90^{\circ} \mathrm{N}$ & $-5 \pm 3$ & $-7 \pm 4$ & $-3 \pm 5$ \\
& $30^{\circ}-60^{\circ} \mathrm{N}$ & $-5 \pm 2$ & $-5 \pm 2$ & $-4 \pm 4$ \\
& $0^{\circ}-30^{\circ} \mathrm{N}$ & $-1.9 \pm 1.6$ & $-2.1 \pm 2.4$ & $-0.2 \pm 3.2$ \\
\hline January & $60^{\circ}-90^{\circ} \mathrm{S}$ & $-31 \pm 17$ & $-29 \pm 14$ & $-12 \pm 5$ \\
& $30^{\circ}-60^{\circ} \mathrm{S}$ & $-5 \pm 3$ & $-14 \pm 3$ & $-11 \pm 5$ \\
& $0^{\circ}-30^{\circ} \mathrm{S}$ & $-2.0 \pm 1.9$ & $-5.0 \pm 2.3$ & $-2.1 \pm 3.7$ \\
\hline
\end{tabular}



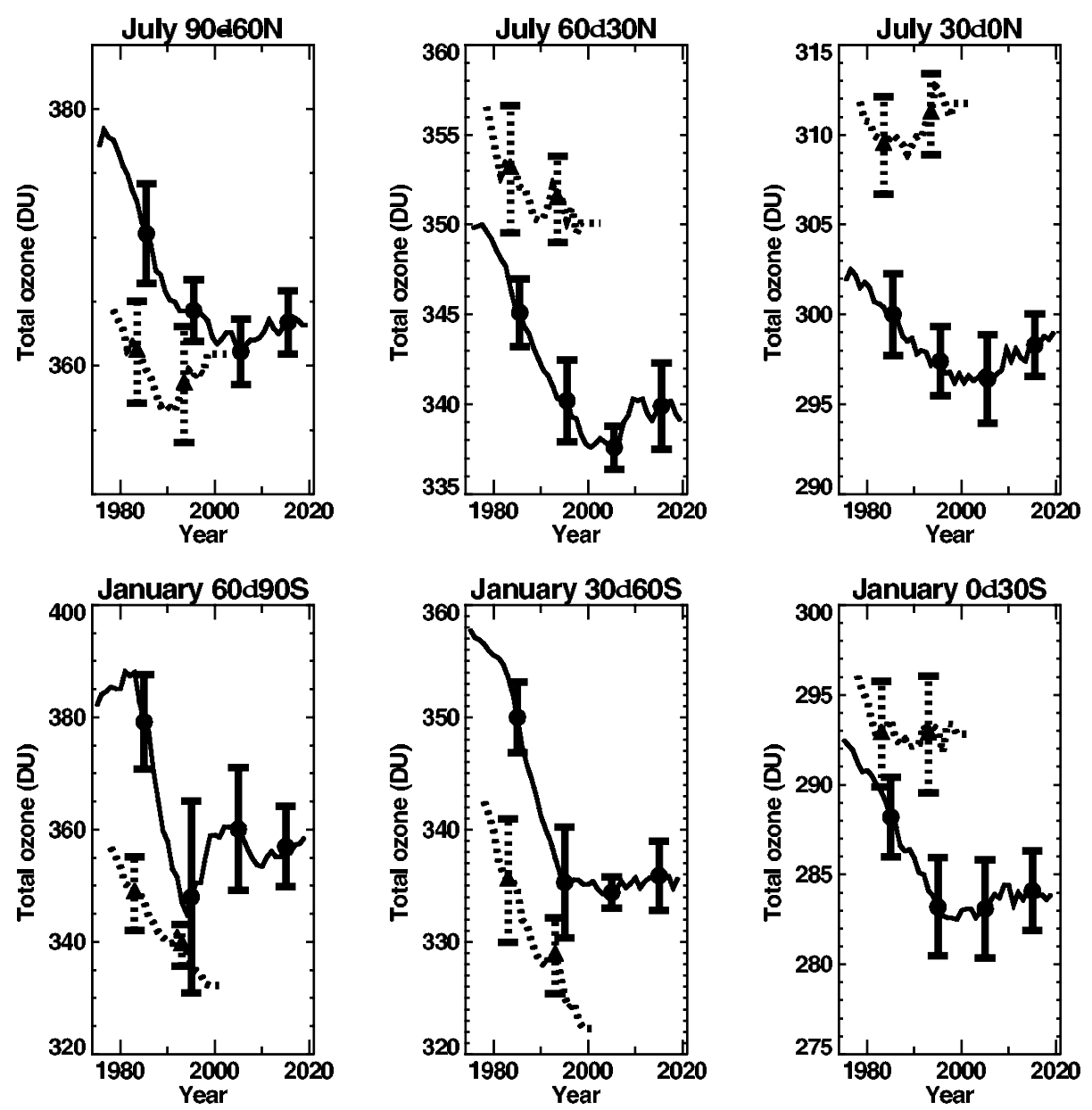

Figure 11. As Fig. 10, but for the months of July (northern hemisphere) and January (southern hemisphere).

the year 2000 onwards, indicating no further ozone loss from the current atmosphere, but no substantial recovery either.

The results for the summer months are shown in the lower half of Table 3 and Fig. 11. In the northern hemisphere, although some of the trends are significant for run GWF, none of them are very large. In the southern hemisphere for January, the observations indicate a decrease in middle and high latitudes, which is possibly a remnant of the Antarctic ozone hole. The midlatitude trend is reproduced only in run GWF but both runs indicate excessive trends in high latitudes. This is probably because the simulated ozone hole tends to persist longer than observed. In the tropics, TOMS indicates a negative trend which is not statistically significant, whereas run GWF has a slightly larger trend which is significant.

The start of recovery, as indicated by the minima in the curves, occurs in about the year 2000 in the southern hemisphere and about 5 years later in the northern hemisphere. However, as in the spring period, although the decrease since 1980 is significant, within the regions shown the ozone recovery after the year 2000 is not statistically significant. 
(a)

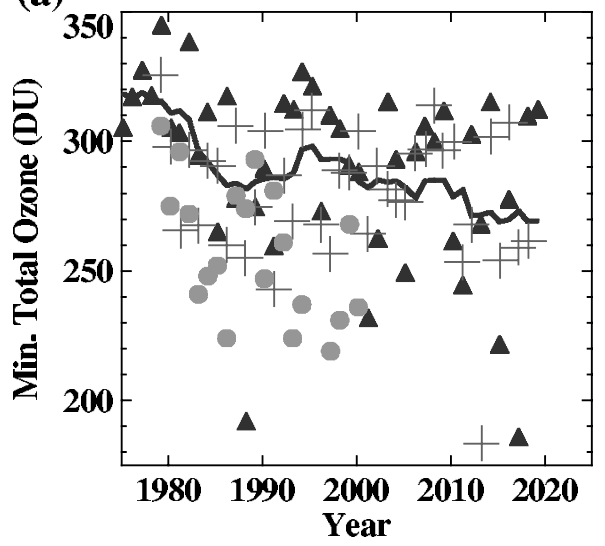

(c)

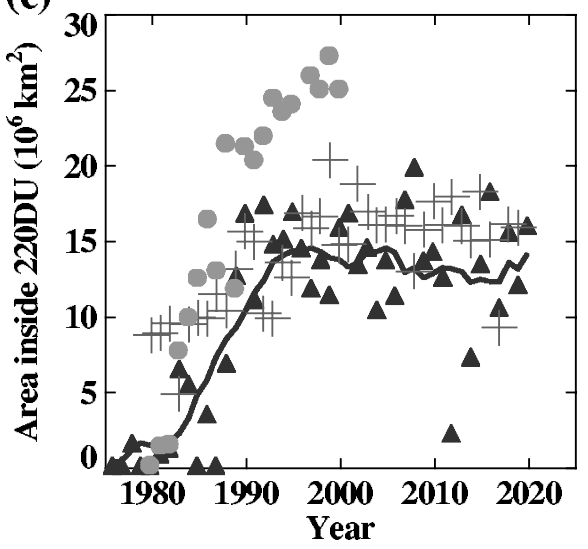

(b)

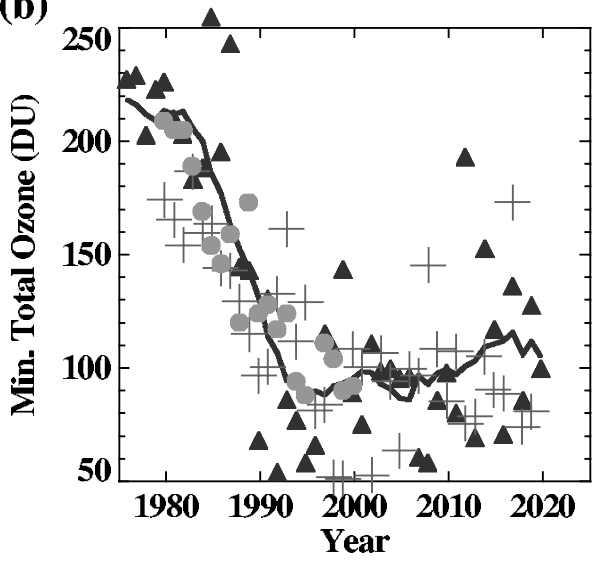

Figure 12. Minimum ozone during the spring seasons for (a) the Arctic and (b) the Antarctic from Total Ozone Mapping Spectrometer (TOMS) observations and the Rayleigh Function (RF) and Gravity-Wave Forcing (GWF) model simulations discussed in this work. (c) Shows the area of the southern hemisphere ozone hole. The solid line indicates the decadally averaged results for run GWF. At the beginning and end of the record, one-sided averages are plotted.

\section{(b) The recovery of minimum total ozone}

Because of their impact on peak UV levels, minimum ozone values attained during each season are shown in Fig. 12 in comparison with TOMS data. In the Arctic (Fig. 12(a)) both GWF and RF simulations are biased high relative to TOMS data. For the same period as used for the regional average, both simulations have a slight downward trend ( $-6 \pm 24$ for run GWF and $-6 \pm 16$ DU/decade for run RF), but neither trend is statistically significant and they are both smaller than the trend in the TOMS data ( $-21 \pm 18 \mathrm{DU} / \mathrm{decade})$. The GWF results have larger interannual variability than the observations and run RF, which gives rise to a larger uncertainty in the determination of the trend. In the decadally averaged model values, there is no indication of an increase in ozone before the year 2020, suggesting a late start to recovery in Arctic minimum ozone. Indeed, if anything, ozone decreases to the end of the integration.

In the Antarctic spring (Fig. 12(b)) the smoothed model results are in better agreement with TOMS than for the Arctic. The size of the trend in run RF 
(a)

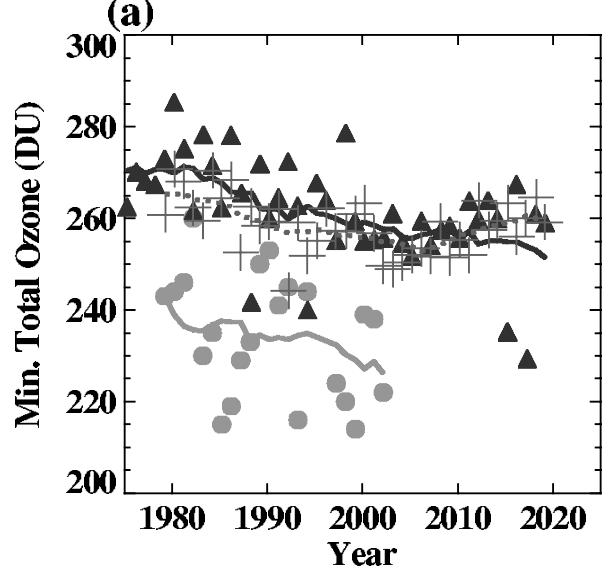

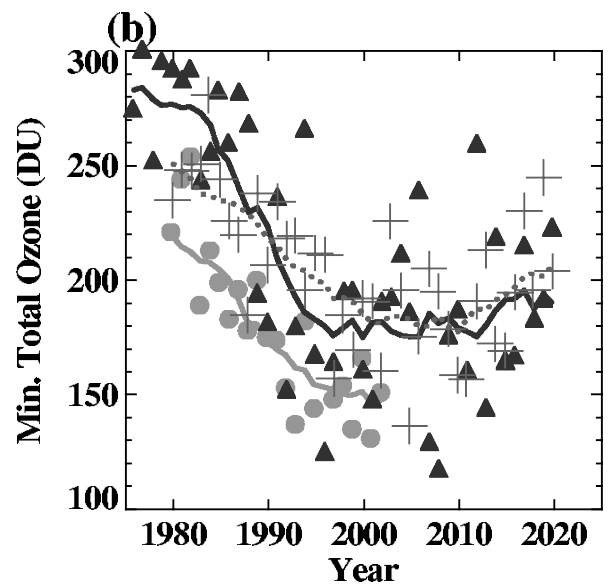

Figure 13. Minimum ozone during the spring seasons for (a) northern midlatitudes and (b) southern midlatitudes. The dark solid line and dotted lines indicate the decadally averaged results for Gravity-Wave Forcing and Rayleigh Friction runs respectively. The light solid line indicates the decadally averaged results for Total Ozone Mapping Spectrometer data. At the beginning and end of the record, one-sided averages are plotted. Other symbols are as in Fig. 12.

$(51 \pm 16 \mathrm{DU} /$ decade $)$ is smaller than in TOMS $(61 \pm 12)$ whereas in run GWF the size of the downward trend $(79 \pm 31$ DU/decade) is larger than observed. Nonetheless, all three results agree within the uncertainty limits, which are particularly large in run GWF, again because of the larger interannual variability. In the decadally averaged results, the minimum for run GWF occurs in the year 2004 and in 1999 in run RF. The maximum size of the ozone hole (Fig. 12(c)) gradually increases from about the year 1980, as observed, and reaches its maximum extent in the mid 1990s, and is essentially a mirror image of the ozone minimum in Fig. 12(b). However, the ozone hole is much smaller than observed. This is due to the high temperature bias in middle to high latitudes in the lower stratosphere of the southern hemisphere (see Fig. 2). In turn this is related to a probable enhanced transport in middle latitudes (see Austin et al. 2003, Fig. 2).

Trends have been computed for the period January 1979 to December 1999 and, as in the case of the regionally averaged results shown in Table 3, the results are very sensitive to the period chosen, particularly in the Arctic. For example, extending the period of the trend calculation to the year 2002 gives an Arctic minimum trend of $-13 \pm 17$ DU/decade. In general, the Arctic minimum values have smaller trends than the regional average but have a similar variability. Therefore, the regionally averaged statistic might be a better indicator of the detection of ozone recovery in high northern latitudes. In contrast, in the Antarctic, the minimum trends are larger than the area mean trends and the minimum may be a better indicator of ozone recovery there.

For midlatitudes, similar results are shown in Fig. 13. As noted previously for other diagnostics (e.g. global ozone, Fig. 6), the model simulations are biased high in northern midlatitudes (Fig. 13(a)) by about 30 DU. Although the statistical significance is low, the observed trends in the minima, again over the period January 1979 to December 1999, are nonetheless well reproduced by both model simulations (TOMS $-7 \pm 11$ DU/decade; run GWF $-7 \pm 8$; run RF $-6 \pm 4$ ). The decadally averaged minima occur in the year 2006 for run RF but not before 2019 for run GWF. However, the low interannual variability for run RF indicates that the observed variability is not 
being represented and perhaps makes this prediction less reliable than the results for run GWF.

The decadally averaged model results for southern midlatitudes (Fig. 13(b)) show a large ozone loss, probably due to transport from the ozone hole, with a possible slight increase in the second half of the simulations. The uncertainty in the trend is again large for run GWF, because of the large interannual variability, but all three results are in agreement for the trend (TOMS $-45 \pm 14$ DU/decade; run GWF $-69 \pm 24$; run RF $-38 \pm 14$ ). The minimum in the decadally averaged values occurs in year 2005 for run RF and in 1999 for run GWF.

Comparisons with section 5(a) indicate that the observed trend in northern midlatitude ozone, averaged over latitudes $30-60^{\circ}$, has a larger statistical significance than the trend in the local minimum ozone presented here, in contrast to the southern hemisphere. Thus, while minimum midlatitude ozone is of concern because of the potential surface UV exposure, there may well be a strong dilution effect in the north which has reduced the magnitude of the midlatitude trends and will make recovery more difficult to detect with this diagnostic.

\section{DisCUSSION AND CONCLUSION}

\section{(a) Comparison of model runs}

In this paper, results from two coupled chemistry-climate model simulations have been presented for the recent past and out to the year 2020. One simulation (denoted RF) used Rayleigh friction to decelerate the polar night jet and the other (denoted GWF) used a spectral gravity-wave forcing scheme. As found by other authors using different models (e.g. Manzini and McFarlane 1998), the cold pole problem was considerably reduced by using a spectral gravity-wave forcing scheme. In principle, this would have had a very significant impact on the simulated ozone climatology as the heterogeneous chemistry is highly temperature-sensitive. In practice, in previous simulations of the RF model, it was found necessary to increase the temperatures in the heterogeneous chemistry scheme to allow for the poor simulation of the temperature climatology. Otherwise the model ozone climatology would have been very unrealistic. With the GWF scheme, this was not necessary and although the trends in the two simulations were similar, the GWF run was in better agreement with observations in middle latitudes. Nonetheless, the weaker southern hemisphere polar-night jet indirectly led to increased interannual variability in a number of parameters, increasing the uncertainties of the trends in temperature and ozone. With these provisos, the fact that the calculated trends in temperature and ozone were similar in the two runs indicated that the globally averaged trends arose largely from changes in external parameters (halogen amounts, greenhouse gas concentrations, sea surface temperatures and ice) rather than model internal variability.

\section{(b) Comparison of model results with observations}

The simulated past temperature trends were in general agreement with satellite data throughout most of the stratosphere, except in the middle stratosphere. As noted by Shine et al. (2003), the results can be improved by including the radiative impacts of water vapour trends, which are much smaller in the current model than observed (Austin 2002). Although total ozone was biased high in both simulations, the past column ozone trends were found to be generally similar to those observed by the TOMS, but with run GWF simulating a larger trend. In practice, this is likely to be more consistent with the observed trends, after allowing for a tropospheric ozone increase. 
Both runs simulated the trends associated with the Antarctic ozone hole. In the Arctic spring, model ozone trends were smaller than observed, particularly in run RF but, because of the large interannual variability, both runs were still consistent with observations. In the Arctic both observations and model trends are strongly affected by interannual variability and therefore it is unclear to what extent the observed trends are due to internal atmospheric variability or due to the external parameters of the system. This issue is explored further in WMO (2003), Chapter 3. In comparison, in the Antarctic spring, the ozone change is much larger and the observed standard deviation from the secular trend is relatively small.

\section{(c) Future trends}

After about the year 2000, the trend in the annually averaged ozone changed in the model simulations. The change was found to be statistically significant in the upper stratosphere almost from pole to pole and in the lower stratosphere over Antarctica. These are the regions most affected by halogen chemistry. In the upper stratosphere, the trend changed from a decrease exceeding $400 \mathrm{ppbv} /$ decade $(6 \% / \mathrm{dec}$ ade) for $1980-2000$ to an increase of over $100 \mathrm{ppbv/decade} \mathrm{(1-2 \% /decade)} \mathrm{for} \mathrm{2000-20} \mathrm{in} \mathrm{some} \mathrm{places.}$

These changes in ozone trend had a corresponding impact on the temperature trends which were higher during the first half of the simulations than the second half. The regions where the differences were of highest statistical significance were the upper stratosphere and the lower stratosphere, where again ozone has a major impact on the cooling rates (Shine et al. 2003).

\section{(d) Trend attribution}

Relatively few locations indicated significance in the temperature trend difference at the $95 \%$ confidence level. This suggests that if one were concerned with the problem of attribution of past and future temperature trends, the upper stratospheric is the best region to investigate, but it may be necessary to complete an ensemble of simulations or its equivalent. Instead of an ensemble, the computational burden might be shared by a number of groups carrying out similar experiments but with different models (e.g. Austin et al. 2003; Shine et al. 2003). Alternatively, a more complete analysis of a given set of results might involve spatial averaging using either geometric coordinates (latitude, longitude) or derived coordinates such as equivalent latitude or empirical orthogonal functions.

For large impacts, such as the effect of the Antarctic ozone hole, and the effect of upper stratospheric ozone recovery, the results here suggest that two integrations are sufficient to attribute the temperature trends to the ozone trends. For example, for run RF, the November trend difference (1980-99 minus 2000-19) averaged over the latitude range $75^{\circ}$ to $90^{\circ} \mathrm{S}$ and pressure range 30 to $150 \mathrm{hPa}$, was $-5.4 \pm 4.4 \mathrm{~K} / \mathrm{decade}$, compared with $-6.5 \pm 8.9 \mathrm{~K} /$ decade for run GWF. Thus, there is a statistically significant difference in run RF, but the large interannual variability in run GWF has reduced the statistical significance of the trends, implying the need for an ensemble of at least two members.

\section{(e) Ozone recovery}

There are many ways of assessing whether ozone recovery has begun. In this work we have used decadally averaged column ozone amounts to estimate the timing of the start of ozone recovery. The temporal averaging reduces the statistical noise which is present in the model results (and presumably would be in the future atmosphere) 
to enable a clearer analysis to emerge. Depending on the chosen ozone characteristicminimum value, temporal mean value or regionally averaged value — a slightly different timing for the start of recovery is obtained.

Both model simulations indicate no substantial further ozone loss from the current atmosphere with minima typically occurring in the years 2000 to 2005, except in the spring Arctic where ozone values continued to decrease to the end of the integrations (January 2020). Higher statistical significance is generally provided by averaging over wide latitude bands, which may prove to be better for the detection of ozone recovery. However, in middle latitudes where the population density is higher, minimum ozone may be of more concern because of the UV impact. Minimum ozone may be dominated by transport from high latitudes, and thus future statistics based on model ozone values averaged over a midlatitude band may have different recovery properties than the minimum.

The results presented here, in indicating no substantial recovery before the year 2020, support the previous analysis of Weatherhead et al. (2000). Their study used twodimensional model results together with observed interannual variability to suggest that the detection of ozone recovery might take even longer than indicated here, and would be at least 20 years depending on latitude. Weatherhead et al. (2000) also identified southern midlatitudes as a region where the earliest recovery might be detected, but we see no unambiguous indication of this in the model simulations.

\section{(f) Future uncertainties}

A major problem with the detection of the start of ozone recovery is that the concentrations of halogens are only expected to reduce slowly from their peak value, although climate change may eventually speed this up (Butchart and Scaife 2002). Indeed, due to the continued release of halons from fire extinguishers, the effective halogen amount in the atmosphere is likely to increase, and then to decrease only slowly, as indicated in Table 1 . Therefore the fact that a large ozone recovery was not simulated by the model before 2020 is not surprising. Another important consideration is the interaction with stratospheric climate change and whether this delays the onset of recovery, as suggested by Austin et al. (1992) and Shindell et al. (1998). This is discussed elsewhere in the light of more recent evidence (e.g. Austin et al. 2001; WMO 2003, Chapter 3 ) but it must be concluded that the effects are rather subtle and difficult to discern from the limited number of simulations completed to date. For example, increases in $\mathrm{CO}_{2}$ amounts will cool the stratosphere, slow the ozone catalytic cycles and accelerate ozone recovery for the bulk of the atmosphere. On the other hand, heterogeneous chemistry plays a major role in the ozone losses reported over the poles and in midlatitudes, and this will slow down or reverse ozone recovery. This picture is further complicated by any changes in the transport of ozone by planetary waves, which are themselves difficult to predict with current climate models. The net result is that it is difficult to ascertain precisely what the overall greenhouse gas effect is, and the timing of ozone recovery is equally difficult to establish.

Therefore there is a need for further model improvements and further model simulations to address issues such as the bias in globally averaged total ozone, and to include a tropospheric chemistry component. Also, the fact that ozone recovery is difficult to detect before 2020 suggests the need to continue the model simulations, with UMETRAC and with other models worldwide, until the second half of this century to establish the timing of complete ozone recovery. 


\section{ACKNOWLEDGEMENTS}

We would like to thank G. Vaughan and two anonymous referees for their help in improving the paper. This work was supported by the UK Department of the Environment, Food and Rural Affairs (contract number EPG/1/1/83), the Government Meteorological Research programme, and the 'European project on Stratospheric Processes and their Impact on Climate and the Environment' of the European Framework 5 programme. We would like to thank the TOMS team for making available TOMS data version 7 from CDs and from the website http://jwocky.gsfc.nasa.gov. Solar flux data were obtained from the NOAA website ftp://ftp.ngdc.noaa.gov/STP/SOLAR_ DATA/SOLAR_RADIO/FLUX.

Austin, J.

Austin, J., Butchart, N. and Shine, K. P.

Austin, J., Driscoll, C. M. H., Farmer, S. F. G. and Molyneux, M. J.

Austin, J., Langematz, U., Dameris, M., Pawson, S., Pitari, G., Shine, K. P. and Stordal, F.

Austin, J., Shindell, D., Brühl, C., Dameris, M., Manzini, E., Nagashima, T., Newman, P., Pawson, S., Pitari, G.,

Rozanov, E., Schnadt, C. and Shepherd, T. G.

Butchart, N. and Scaife, A. A.

Butchart, N., Austin, J., Knight, J. R., Scaife, A. A. and Gallani, M. L.

Butchart, N., Scaife, A. A., Austin, J., Hare, S. H. E. and Knight, J. R.

Carslaw, K. S., Luo, B. P., Clegg, S. L., Peter, T., Brimblecombe, P. and Crutzen, P. J.

DeMore, W. B., Sander, S. P., Golden, D. M.,

Hampson, R. F., Kurylo, M. J., Howard, C. J.,

Ravishankara, A. R. Kolb, C. E. and Molina, M. J.

Goutail, F., Pommereau, J.-P., Phillips, C., Deniel, C., Sarkissian, A., Lefèvre, F., Kyro, E., Rummukainen, M., Ericksen, P., Andersen, S., Kaastad-Hoiskar, B. A., Braathen, G., Dorokhov, V. and Khattatov, V.

\section{REFERENCES}

2002 A three-dimensional coupled chemistry-climate model simulation of past stratospheric trends. J. Atmos. Sci., 59, 218-232

1992 Possibility of an Arctic ozone hole in a doubled-CO $\mathrm{CO}_{2}$ climate. Nature, 360, 221-225

1999 Late spring ultraviolet levels over the United Kingdom and the link to ozone. Annales Geophysicae, 17, 1199-1209

2001 European Research in the Stratosphere 1996-2000; Advances in our understanding of the ozone layer during THESEO. Directorate-General for Research, Environment and sustainable development programme, Office for Official Publications of the European Communities, EUR 19867, Chapter 5, $191-222$

2003 Uncertainties and assessments of chemistry-climate models of the stratosphere. Atmos. Chem. Phys., 3, 1-27

2002 Removal of chlorofluorocarbons by increased mass exchange between the stratosphere and troposphere in a changing climate. Nature, 410, 799-802

2000 The response of the stratospheric climate to projected changes in the concentrations of the well-mixed greenhouse gases from 1992 to 2051. J. Climate, 13, 2142-2159

2003 Quasi-biennial oscillation in ozone in a coupled chemistryclimate model. J. Geophys. Res., 108, D15, doi: 10.1029/ 2002 JD 003004

1994 Stratospheric aerosol growth and $\mathrm{HNO}_{3}$ gas phase depletion from coupled $\mathrm{HNO}_{3}$ and water uptake by liquid particles. Geophys. Res. Lett., 21, 2479-2482

1997 Chemical kinetics and photochemical data for use in stratospheric modeling. Evaluation number 12, JPL Publication 97-4, Pasadena, CA, USA

1999 Depletion of column ozone in the Arctic during the winters 1993-94 and 1994-95. J. Atmos. Chem., 32, 1-34 
Hein, R., Dameris, M., Schnadt, C., Land, C., Grewe, V., Kohler, I., Ponater, M., Sausen, R., Steil, B., Landgraf, J. and Brühl, C.

Herman, J. R., Bhartia, P. K., Ziemke, J., Ahmad, Z. and Larko, D.

Intergovernmental Panel on Climate Change

Manzini, E. and McFarlane, N. A.

Manzini, E., Steil, B., Brühl, C., Giorgetta, M. A. and Krüger, K.

Nagashima, T., Takahashi, M., Takigawa, M. and Akiyoshi, $\mathrm{H}$.

Pawson, S. and coauthors

Roscoe, H. K., Jones, A. E. and Lee, A. M.

Randel, W. J. and Wu, F.

Sander, S. P., Ravishankara, A. R. Friedl, R. R., Demore, W. B., Golden, D. M., Kolb, C. E., Kurylo, M. J., Molina, M. J., Hampson, R. F., Huie, R. E. and Moortgat, G. K.

Scaife, A. A., Austin, J. Butchart, N., Keil, M. Pawson, S., Nash, J. and James, I. N.

Scaife, A. A., Butchart, N., Warner, C., Stainforth, D., Norton, W. and Austin, J.

Scaife, A. A., Butchart, N., Warner, C. D. and Swinbank, R.

Shindell, D. T., Rind, D. and Lonergan, $\mathrm{P}$.

Shine, K. P., Bourqui, M. S., Forster, P. M. de F., Hare, S. H. E., Langematz, U., Braesicke, P., Grewe, V., Schnadt, C., Smith, C. A. Haigh, J. D., Austin, J., Butchart, N., Shindell, D., Randel, W. J., Nagashima, T., Portmann, R. W., Solomon, S., Seidel, D., Lanzante, J.,

Klein, S., Ramaswamy, V. and Schwarzkopf, M. D.

Swinbank, R. and O'Neill, A.
2001

Results of an interactively coupled atmospheric chemistry-general circulation model: comparison with observations. Annales Geophysicae, 19, 435-457

UV-B increases 1979-1992 from decreases in total ozone Geophys. Res. Lett., 23, 2117-2120

Climate change: the supplementary report to the IPCC scientific assessment. Eds. J. T. Houghton, B. A. Callander and S. K. Varney, Cambridge University Press, Cambridge, UK

Climate change 2001: The scientific basis. Third Assessment Report. Eds. J. T. Houghton, X. Ding, D. J. Griggs, M. Noguer, P. J. van der Linden, X. Dai, K. Maskell and C. A. Johnson. Cambridge University Press, Cambridge, UK

The effect of varying the source spectrum of a gravity wave parameterization in a middle atmosphere general circulation model. J. Geophys. Res., 103, 31523-31539

A new interactive chemistry-climate model: 2. Sensitivity of the middle atmosphere to ozone depletion and increase in greenhouse gases and implications for recent stratospheric cooling. J. Geophys. Res., 108, 4429. doi: 10.1029/ 2002JD002977

Future development of the ozone layer calculated by a general circulation model with fully interactive chemistry. Geophys. Res. Lett., 10.1029/2001GL014026

The GCM-reality intercomparison project for SPARC (GRIPS): Scientific issues and initial results. Bull. Am. Meteorol. Soc. 81, 781-796

Midwinter start to Antarctic ozone depletion: evidence from observations and models. Science, 278, 93-96

A stratospheric ozone data set for global modeling studies. Geophys. Res. Lett., 26, 3089-3092

Chemical kinetics and photochemical data for use in stratospheric modeling. Evaluation number 12: Updata of key reactions, JPL Publication 00-3, Pasadena, CA, USA

Seasonal and interannual variability of the stratosphere diagnosed from UKMO TOVS analyses. Q. J. R. Meteorol. Soc., 126, 2585-2604

Realistic Quasi-Biennial Oscillations in a simulation of the global climate. Geophys. Res. Lett., 27, 3481-3484

Impact of a spectral gravity wave parameterization on the stratosphere in the Met Office Unified Model. J. Atmos. Sci., 59, 1473-1489

Increased polar stratospheric ozone losses and delayed eventual recovery owing to increasing greenhouse-gas concentrations. Nature, 392, 589-592

A comparison of model-predicted trends in stratospheric temperatures. Q. J. R. Meteorol. Soc., 129, 1565-1588

A stratosphere-troposphere data assimilation system. Mon. Weather. Rev., 122, 686-702 
Weatherhead, E. C., Reinsel, G. C., 1998 Tiao, G. C., Meng, X.-L.,

Choi, D., Cheang, W.-K.,

Keller, T., DeLuisi, J.,

Wuebbles, D. J., Kerr, J. B.,

Miller, A. J., Oltmans, S. J.

and Frederick, J. E.

Weatherhead, E. C., Reinsel, G. C., 2000

Tiao, G. C., Jackman, C. H.,

Bishop, L.,

Hollandsworth Frith, S. M.,

DeLuisi, J., Keller, T.,

Oltmans, S. J., Fleming, E. L.,

Wuebbles, D. J., Kerr, J. B.,

Miller, A. J., Herman, J.,

McPeters, R., Nagatani, R. M. and Frederick, J. E.

Williams, K. D., Senior, C. A. and Mitchell, J. F. B.

World Meteorological

Organization/United Nations

Environment Programme

Zerofos, C. S., Tourpali, K.,

Bojkov, B. R. and Balis, D. S.
2001

1999

2003

1997
Factors affecting the detection of trends: statistical considerations and applications to environmental data. J. Geophys. Res., 103, 17149-17161

Detecting the recovery of total column ozone. J. Geophys. Res., 105, 22201-22210

Transient climate change in the Hadley Centre models: the role of physical processes. J. Climate, 14, 2659-2674

Scientific Assessment of Ozone Depletion: 1998. World Meteorological Organization, Global Ozone Research and Monitoring Project - Report No. 44, obtainable from WMO Global Ozone Observing System, PO Box 2300, 1211-Geneva-2, Switzerland

Scientific Assessment of Ozone Depletion: 2002. World Meteorological Organization, Global Ozone Research and Monitoring Project - Report No. 47.

Solar activity-total ozone relationships: Observations and model studies with heterogeneous chemistry. J. Geophys. Res., 102, 1561-1569 